\title{
A FALIBILIDADE DO ALGORITMO CONTENT ID NA IDENTIFICAÇÃO DE VIOLAÇÕES DE DIREITO AUTORAL NOS VLOGS DO YOUTUBE: EMBATES SOBRE LIBERDADE DE EXPRESSÃO NA CULTURA PARTICIPATIVA
}

\author{
Jordana Siteneski do Amaral ${ }^{1}$ \\ Salete Oro Boff ${ }^{2}$
}

\begin{abstract}
RESUMO: Este trabalho buscou verificar se o uso do algoritmo Content ID pelo site YouTube, como ferramenta para identificação de violações de direito autoral, pode gerar conflitos entre liberdade de expressão e direitos autorais. Utilizando o método de pesquisa hipotético-dedutivo e a técnica bibliográfica foi possível auferir que o algoritmo possui grande falibilidade na aplicação prática, pois pode ser burlado para cometimento de pirataria, ao mesmo tempo que aponta violações de direito autoral que de fato, não ocorreram. $\mathrm{O}$ algoritmo não analisa possíveis casos de limitações de direito de autor, uma vez que os algoritmos trabalham com soluções lógicas para problemas idênticos.
\end{abstract}

Palavras Chave: Vlogs; Cultura Participativa; Direito Autoral; Algoritmo; Uso Aceitável.

\section{THE ALGORITHM CONTENT ID FAILURE IN IDENTIFYING COPYRIGHT VIOLATIONS IN YOUTUBE VLOGS: DISCUSSIONS ABOUT FREEDOM OF EXPRESSION IN PARTICIPATORY CULTURE}

\begin{abstract}
This work sought to verify if the use of the Content ID algorithm by the YouTube site, as a tool to identify copyright violations, can generate conflicts between freedom of expression and copyright. Using the hypothetical-deductive research method and the bibliographical technique it was possible to infer that the algorithm has a great fallibility in the practical application, since it can be circumvented to commit piracy, while at the same time pointing out copyright violations that did not occur. The algorithm does not analyze possible cases of fair use, since the algorithms work with logical solutions to the same problems.
\end{abstract}

Keywords: Vlogs; Participatory Culture; Copyright; Algorithm; Fair Use.

\footnotetext{
${ }^{1}$ Mestranda do PPG/DIREITO da Faculdade Meridional (IMED), com bolsa Taxa CAPES/PROSUP. Membro do Grupo de estudos GEDIPI e do Grupo de Pesquisa "Direito e Novas Tecnologias". Graduada em Direito pela Faculdade Meridional. Graduada em Comunicação Social (Jornalismo) pela Universidade de Passo Fundo. Membro do Grupo de Pesquisa "Processos e Práticas Culturais em Comunicação". E-mail: jo.siteneski@ hotmail.com; Lattes: http://lattes.cnpq.br/5581775588287895. O presente trabalho foi realizado com apoio da Coordenação de Aperfeiçoamento de Pessoal de Nível Superior - Brasil (CAPES) - This study was financed in part by the Coordenação de Aperfeiçoamento de Pessoal de Nível Superior - Brasil (CAPES).

${ }^{2}$ Pós-Doutora em Direito em 2008 pela Universidade Federal de Santa Catarina (UFSC). Doutora em Direito em 2005 pela Universidade do Vale dos Sinos (UNISINOS). Mestre em Direito em 2000 pela Universidade do Vale dos Sinos (UNISINOS). Especialista em Direito Público em 1998 pela Universidade Regional do Noroeste do Estado do Rio Grande do Sul (UNIJUI). Graduada em Direito em 1992 pela Universidade Regional do Noroeste do Estado do Rio Grande do Sul (UNIJUI). E-mail: salete.oro.boff@gmail.com
}

Rev. de Direito, Inovação, Propriedade Intelectual e Concorrência | e-ISSN: 2526-0014 | Porto Alegre | v. 4 | n. 2 | p. 43-62 | Jul/Dez. 2018 


\section{INTRODUÇÃO}

As novas tecnologias em conjunto com as mídias digitais possibilitaram aos consumidores de produtos midiáticos saírem da posição de receptores passivos em direção à conexão e à interatividade ininterrupta. Muitos teóricos buscam compreender o fenômeno cultural e social que envolve a inserção dessas ferramentas nas sociedades. Fala-se no surgimento uma cultura mais participativa e colaborativa, de convergência midiática, e de consumidores que querem participar ativamente da produção de mensagens e conteúdo, agindo como co-criadores ${ }^{3}$. Mas a interatividade traz também vários questionamentos e, no âmbito jurídico, o Direito Autoral foi um dos que mais sofreu impactos com as novas tecnologias.

Com cultura participativa, a ideia consolidada sobre "consumidores e produtores" de mídia como ocupantes de papeis estratificados, deve ser revista. Os fãs de um seriado, filme ou romance podem fazer capturas de diálogos no vídeo, fazer resenhas e resumos, discutir em fóruns e chats sobre aquela série, criar e divulgar seus próprios filmes, paródias, criar fanarts, e escrever fanfics $^{4}$ (JENKINS, 2009).

Um fenômeno que tem crescido nos últimos anos é o videoblog, ou simplesmente, vlog nos sites de streaming de vídeo. No Brasil, o mais popular e utilizado é o YouTube, onde muitos vloggers começaram criando seus canais e postando seus primeiros vídeos. Tem-se que esses vlogs fazem parte desta cultura participativa nas mídias digitais. Muitas vezes esses vídeos usam materiais de autoria de terceiros, como trechos de outros vídeos, músicas, filmes, desenhos animados, séries e games.

O site YouTube, onde muitos desses vídeos estão hospedados, possui uma política de direitos autorais própria e também ferramentas para coibir violações de direito autoral. Ocorre que estas ferramentas são criticadas de forma constante, por sua rigidez e por não impedirem violações de direito de autor. O que se vê, ao contrário, é que podem abrir espaço para abusos

3 Frequentemente, são referidos como prosumers (produtor-consumidor). Ver: CAMARGO, Isadora; ESTEVANIM, Mayanna; SILVEIRA, Stefanie C. da. Cultura participativa e convergente: o cenário que favorece o nascimento dos influenciadores digitais. In: Revista Comunicare, Revista semestral do Centro Interdisciplinar de Pesquisa da Faculdade Cásper Líbero, Volume 17. São Paulo, 2017 Disponível em: < https://casperlibero.edu.br/wp-content/uploads/2017/09/Artigo-5-Communicare-17-Edi\%C3\%A7\%C3\%A30Especial.pdf>; e SAAD, Elizabeth; RAPOSO, João Francisco. Prosumers: colaboradores, cocriadores e influenciadores. Revista Comunicare, volume 17, Disponível em <: https://casperlibero.edu.br/wpcontent/uploads/2017/09/Artigo-6-Communicare-17-Edi\%C3\%A7\%C3\%A3o-Especial.pdf> Acesso em 03 junho de 2018.

${ }^{4}$ Sobre a temática de Fanfics e Direito Autoral ver: AMARAL, Jordana Siteneski do; BOFF, Salete Oro. Uma obra e vários autores: o direito autoral e as "fan-fictionals" na cultura da convergência. In: Scientia Iuris, Londrina, v. 22, n. 1, p.162-189, mar. 2018. Disponível em: < http://www.uel.br/revistas/uel/index.php/iuris/article/view/29964> Acesso em 03 junho de 2018. 
A FALIBILIDADE DO ALGORITMO CONTENT ID NA IDENTIFICAÇÃO DE VIOLAÇÕES DE DIREITO AUTORAL NOS VLOGS DO YOUTUBE: EMBATES SOBRE LIBERDADE DE EXPRESSÃO NA CULTURA PARTICIPATIVA

no uso do Direito de Autor, prejudicando a liberdade de expressão e a criação de conteúdo independente.

Uma destas ferramentas, objeto de análise neste artigo é o algoritmo Content ID. Este algoritmo ainda traz certa insegurança para o usuário, pois existem relatos de falhas na sua aplicação, sendo extremamente rígido em alguns casos e, por outro lado, pode ser burlado para prática de pirataria.

O problema de pesquisa deste trabalho consiste em verificar se o uso de algoritmos pelo site de streaming YouTube, como ferramenta para identificação de violações de direito autoral, pode gerar conflitos entre liberdade de expressão e direitos autorais?

O assunto requer aprofundamento, uma vez que o uso de algoritmos para esta finalidade poderá se expandir para outras plataformas, uma vez que esta prática poderá se expandir para outras plataformas. O uso de algoritmos para identificar possíveis violações de direito de autor, que funcionaria de maneira semelhante ao Content ID do YouTube também está sendo cogitado pela rede social Facebook, ainda está em fase de testes (UBC, 2017).

O tema demonstra relevância e pertinência em razão de sua atualidade, bem como por discutir até que ponto um algoritmo é uma forma segura para se verificar e tomar decisões em relação a possíveis situações de violação de direito de autoral, sem que isto se transforme em uma medida excessiva e, até, limitadora da liberdade de expressão.

A hipótese a ser acatada ou refutada é a de que o uso de algoritmos, mais especificamente o Content ID do YouTube, pode gerar conflito entre liberdade de expressão e de direitos autorais, em razão de sua falibilidade na aplicação prática. Isso ocorre porque a lógica de funcionamento do algoritmo é a de buscar correspondências nos vídeos hospedados no site em materiais protegidos por direitos autorais.

Para tanto, este artigo usa como o método de pesquisa hipotético-dedutivo e técnica de pesquisa bibliográfica. Os objetivos deste trabalho consistem em: 1) construir um conceito para os algoritmos na área da informática, compreendendo suas funções e utilizações; 2) conceituar os vlogs e descrever a política de direito autoral adotada pelo YouTube; 3) descrever o funcionamento do algoritmo Contend ID do YouTube; 4) analisar as problemáticas e a falibilidade do algoritmo que podem levar a conflitos entre liberdade de expressão e Direitos Autorais, partindo de casos relatados.

Rev. de Direito, Inovação, Propriedade Intelectual e Concorrência | e-ISSN: 2526-0014 | Porto Alegre | v. 4 | n. 2 | p. 43-62 | Jul/Dez. 2018 


\section{CONCEITO E FUNÇÃO DO ALGORITMO}

O termo algoritmo pode se referir a diferentes funções, de acordo com o dicionário da língua portuguesa. Na matemática, pode ser entendido como um "Processo de cálculo que, por meio de uma sequência finita de regras, raciocínios e operações, aplicada a um número finito de dados, leva à resolução de grupos análogos de problemas.”. (MICHAELIS, 2018)

$\mathrm{Na}$ lógica, o algoritmo pode ser definido como um conjunto das regras de operação (conjunto de raciocínios) cuja aplicação permite resolver um problema enunciado por meio de um número finito de operações. Pode ser aplicado em um programa executado por um computador, detectável nos mecanismos gramaticais de uma língua ou no sistema de procedimentos racionais finitos, utilizado em outras ciências, para resolução de problemas semelhantes (MICHAELIS, 2018).

Buscando a definição na área da ciência da computação, tem-se que os algoritmos fazem parte da subárea da programação, definido como: "um algoritmo pode ser definido como uma sequência finita de passos (instruções) para resolver um determinado problema. Sempre que desenvolvemos um algoritmo estamos estabelecendo um padrão de comportamento que deverá ser seguido para alcançar o resultado de um problema." (FERRARI; CECHINEL, 2018, p.15).

Em seu desenvolvimento é necessário que o programador obedece algumas premissas básicas, tais como: 1) definir ações simples e sem ambiguidade; 2) organizar as ações de forma ordenada; 3) estabelecer as ações dentro de uma sequência finita de passos (FERRARI; CECHINEL, 2018, p.15).

Por meio de algoritmos é possível desempenhar uma série de ações, como por exemplo, ler e escrever dados; avaliar expressões algébricas, relacionais e lógicas; tomar decisões com base nos resultados das expressões avaliadas e repetir um conjunto de ações de acordo com uma condição (FERRARI; CECHINEL, 2018, p.15).

Basicamente, ele é constituído de três elementos: "entrada de dados > processamento de dados > saída de dados". Na entrada, são fornecidas as informações necessárias para que o algoritmo possa ser executado. Estas informações podem ser fornecidas no momento em que o programa está sendo executado, ou ainda, podem já estar embutidas dentro do mesmo. Na parte do processamento são avaliadas todas as expressões algébricas, relacionais e lógicas, assim como todas as estruturas de controle existentes no algoritmo (condição e/ou repetição). Na parte 


\section{A FALIBILIDADE DO ALGORITMO CONTENT ID NA IDENTIFICAÇÃO DE VIOLAÇÕES DE DIREITO AUTORAL NOS VLOGS DO YOUTUBE: EMBATES SOBRE LIBERDADE DE EXPRESSÃO NA CULTURA PARTICIPATIVA}

de saída, todos os resultados do processamento (ou parte deles) são enviados para um ou mais dispositivos de saída (FERRARI; CECHINEL, 2018, p.15).

Atualmente, os algoritmos são muito utilizados nas redes sociais como forma de criar um direcionamento das publicações e temas apresentados aos usuários. Eli Parisier (2011) mostrou que a internet está criando um "filtro invisível" por meio de ferramentas e os algoritmos são uma dessas ferramentas: "Em novembro de 2008, o Google já detinha várias patentes para algoritmos de personalização - códigos capazes de desvendar os grupos aos quais uma pessoa pertence e então adaptar os resultados da pesquisa para que se adequem à preferência do grupo.” (PARISIER, 2011, p.27).

A publicidade nos anúncios ou nos e-mails, sugestões e tudo o que passa na timeline de cada dia é condicionado por uma série de algoritmos. O usuário, sem perceber, passa a ficar dentro de uma "bolha", restrita a personalização do conteúdo que recebe em quase todos os sites da rede. ${ }^{5}$

O uso de algoritmos pode ser benéfico ou maléfico. Pode ser benéfico quando leva a resultados mais justos, como por exemplo, no programa de um algoritmo que ignorem fatores como gênero e raça na seleção de uma vaga de emprego. Por outro lado, pode ser maléfico, a classificação algorítmica pode ser até mais discriminatória em alguns casos, caso o algoritmo "aprenda" a repetir um padrão com base nos candidatos que foram contratados ultimamente (PARISIER, 2011, p.90).

Nesse sentido, os algoritmos funcionam na prática, por meio de indução. Parisier (2011, p.90) ressalva que os algoritmos podem acabar com a falseabilidade das informações ${ }^{6}$, crítica levantada por Karl Popper sobre o método indutivo na ciência. Logo, os algoritmos que buscam por padrões encontram dois desafios:

A construção de algoritmos destinados a encontrar padrões apresenta dois desafios. $\mathrm{O}$ primeiro é encontrar os padrões que existem em meio ao caos. O segundo problema é o oposto: não encontrar padrões que não estejam realmente ali. O padrão que descreve a sequência " $1,2,3$ ” poderia ser "some um ao número anterior" ou "liste os números

\footnotetext{
${ }^{5} \mathrm{O}$ aplicativo de streaming Netflix, trabalha com um algoritmo que, ao verificar um filme assistido pelo usuário, sugere outros títulos de gênero semelhante que outros usuários já assistiram (PARISIER, 2011, p.90).

6 "Popper apresentou o problema de forma ligeiramente diferente: o fato de sempre termos visto cisnes brancos não significa que todos os cisnes sejam brancos. $\mathrm{O}$ que precisamos é procurar é um cisne negro, o contraexemplo que falseie a teoria. "A falseabilidade", afirmava Popper, é a chave na busca da verdade: o propósito da ciência, para Popper, era fazer as maiores afirmações para as quais ninguém conseguisse encontrar exemplos contrários, cisnes negros. A visão de Popper trazia profunda humildade sobre o conhecimento induzido cientificamente - a ideia de que estamos errados com tanta frequência quanto estamos certos, e geralmente não sabemos quando. Essa humildade é o que falta em muitos métodos algorítmicos de previsão. [...] Eles estão interessados em acertar na demografia geral, e não em seres humanos complexos." (PARISIER, 2011, p.92)
} 
primos positivos do menor ao maior". Não podemos ter certeza até obtermos mais dados. E se tirarmos conclusões apressadas, estaremos sobreajustando (PARISIER, 2011, p.90).

No caso das sugestões de filmes, as possíveis consequências são brandas. Mas há que se considerar que "sobreajustar” e estereotipar são sinônimos (PARISIER, 2011, p.90).

Nas redes sociais eles podem ser usados, por exemplo, para "mapear" os sentimentos coletivos em relação a um fato, tema ou publicação. Desde que o Facebook disponibilizou uma ferramenta em que é possível reagir as publicações, além de apenas curtir, é possível ter um "termômetro" que mede as reações da população sobre determinado tema. Ainda, torna possível a empresa fazer uma pesquisa de "contágio emocional”, de criar um “mapeamento psicológico". (CECILIO, 2016, p.89)

Como já indicado, neste artigo, o objetivo é analisar em que medida o uso de algoritmos pode ser efetivo para identificar conflitos de direito autoral, tomando como análise, o algoritmo Content ID do YouTube e suas problemáticas. Como o Content ID não é a única medida destinada a curadoria e implementação da política de direitos autorais do site, o próximo tópico irá explicar como funciona esta política, para em um segundo momento, centrar-se no algoritmo.

\section{OS VLOGS E A POLÍTICA DE DIREITOS AUTORAIS NO YOUTUBE}

O YouTube é o segundo endereço da web mais visitado no Brasil ${ }^{7}$. Muitas pessoas, empresas e instituições possuem contas ou canais no site, os quais assistem, compartilham, produzem conteúdo e fazem uploads de seus próprios vídeos. É possível encontrar tanto o conteúdo produzido por "amadores”, quanto o conteúdo das gigantes industrias de mídia, como gravadoras, canais de televisão, estúdios de cinema e empresas de games.

$\mathrm{Na}$ última década, essas pessoas que produzem e editam seus próprios vídeos na plataforma têm ganhado popularidade. Muitos viraram "celebridades" da internet, ou ainda, em um adjetivo mais contemporâneo, ganharam o status de "digital influencers"

A prática de criar conteúdo e postar na rede é comum desde as primeiras plataformas online, como ocorria nos blogs, populares no final da década de 1990 e início dos anos 2000.

\footnotetext{
7 Atrás apenas do site Google, segundo levantamento do site Alexa. Disponível em: $<$ https://www.alexa.com/topsites/countries/BR $\geq$ Acesso em 26 de junho de 2018.

${ }^{8} \mathrm{Um}$ digital influencer nada mais é do que uma pessoa que produz conteúdo para alguma rede social, que as utiliza para gerara algum tipo de influência de comportamento, reflexão ou pensamento entre seus seguidores (CORUJA, 2017).
}

Rev. de Direito, Inovação, Propriedade Intelectual e Concorrência | e-ISSN: 2526-0014 | Porto Alegre | v. 4 | n. 2 | p. 43-62 | Jul/Dez. 2018 
A FALIBILIDADE DO ALGORITMO CONTENT ID NA IDENTIFICAÇÃO DE VIOLAÇÕES DE DIREITO AUTORAL NOS VLOGS DO YOUTUBE: EMBATES SOBRE LIBERDADE DE EXPRESSÃO NA CULTURA PARTICIPATIVA

Com a popularização das câmeras de vídeo e de aspectos técnicos (conexão, sites de streaming), a produção de conteúdo e postagem foi tomando o formato audiovisual.

Os chamados videoblogs, ou mais comumente chamados de "vlogs $s^{9 ", ~ p o d e m ~ s e r ~}$ compreendidos como uma extensão dos diários pessoais e dos próprios blogs. O criador de conteúdo, o vlogger $^{10}$, pode construir seu canal abordando infinitas temáticas e assuntos, fazendo seu próprio recorte: “Cada vlogger, da mesma forma que os bloggers, retrata um recorte do contexto cotidiano conforme sua própria visão do real.” (DORNELLES, 2015, p.22).

Ou seja, existem muitos usuários que utilizam o YouTube como plataforma de distribuição de seus conteúdos. E assim como qualquer site, o YouTube precisa ter políticas e diretrizes de direito autoral que se submetam e respeitem as legislações. O site possui sua política própria de direitos autorais que está descrita e disponível para todos os usuários que acessam o site, mas de forma mais direcionada, por óbvio, para aqueles que fazem upload de conteúdo no site.

O site oferece quatro diferentes formas de administrar os direitos autorais: a notificação formal, o algoritmo Content ID, o programa de verificação de conteúdo e a ferramenta de correspondências.

O usuário pode fazer uma reivindicação de direitos autorais caso entenda que algum material utilizado por terceiros nos vídeos postados está violando algum direito autoral, ou foi postado sem autorização do detentor desses direitos. Essa reivindicação pode ser feita por meio de uma solicitação de remoção, ou pode ser identificada por meio do Contend ID (YOUTUBE, 2018b).

\footnotetext{
${ }^{9}$ A literatura científica já voltou seus olhos para a pesquisa do fenômeno dos vlogs na atualidade, de forma que algumas considerações são dignas de nota, ainda que este não seja o foco principal deste estudo. Combe e Codreanu (2016) demonstraram que os vlogs podem ser usados como ferramentas de interação, conversação, aprendizagem e alfabetização digital.

${ }^{10}$ Vlogger é o termo usado para se referir as pessoas que produzem conteúdo para um videoblog na internet, que seja hospedado no YouTube ou não. Pertinentes são as colocações de Paula Coruja (2017, p.47) sobre o fenômeno do vlog. De acordo com a autora, ele é um dos reflexos da "cultura participativa" que emana da internet. No YouTube, um conteúdo adquire valor pela sua propagabilidade. $\mathrm{O}$ site não produz vídeos, ele apenas faz a hospedagem, a "curadoria" desses conteúdos produzidos por terceiros. Mas ele ajuda na promoção desses conteúdos criados por usuários, os apresentando na sua página inicial, sugerindo e criando listas de reprodução para quem acessa o site, além dos anúncios de publicidade. Essa curadoria de conteúdo é baseada em algoritmo. Isso permite concluir que, embora exista interação com o usuário e não exista uma "grade de programação" fixa como na mídia televisiva, o YouTube não é uma plataforma em que o conteúdo é absolutamente livre de mediação para chegar ao usuário, pois ele é em parte, sugestionado pelos algoritmos. A plataforma divide os lucros dos anúncios com as pessoas que postam seus vídeos. Isso fez com que, gradativamente, a atividade de youtuber fosse se profissionalizando, ainda que alguns permaneçam no amadorismo.
}

Rev. de Direito, Inovação, Propriedade Intelectual e Concorrência | e-ISSN: 2526-0014 | Porto Alegre | v. 4 | n. 2 | p. 43-62 | Jul/Dez. 2018 
A solicitação de remoção consiste em uma notificação formal de direitos autorais, que deve ser enviada pelo usuário detentor dos direitos violados para a equipe do site contendo todos os requisitos ${ }^{11}$ legais preenchidos.

O site, já ciente de que podem ocorrer tanto enganos quanto abusos nas reivindicações de direito autoral, adverte que possui ferramentas para identificar e coibir essas práticas. Caso o proprietário do vídeo constante que foi afetado por uma notificação indevida, ele tem duas opções: solicitar uma retratação do reclamante ou enviar uma contranotificação ${ }^{12}$.

As outras ferramentas incluem o formulário on-line de notificação de direitos autorais, a ferramenta de correspondência ${ }^{13}$ e o Programa de verificação de conteúdo (CVP, na sigla em inglês) ${ }^{14}$.

\section{O ALGORITMO CONTEND ID}

O Content ID é uma ferramenta utilizada para identificar para identificar e gerenciar o conteúdo no YouTube com facilidade. O Contend ID é um algoritmo que busca e identifica correspondências nos vídeos que são upados para o YouTube e os materiais protegidos por direito autoral. Na prática, ele verifica todo vídeo que é enviado, comparando-o com "banco de dados", ou de "referências", que é formado por arquivos enviados pelos próprios proprietários do conteúdo. Quando uma correspondência for encontrada o vídeo recebe uma reivindicação do Content ID (YOUTUBE, 2018a).

Ao contrário das remoções, o Content ID é um sistema do YouTube executado mediante acordos entre o site e os parceiros de conteúdo que enviaram os materiais para a base

\footnotetext{
${ }^{11}$ Os requisitos para enviar uma solicitação de remoção por direitos autorais válida são: informações de contato, descrição de sua obra, cujos direitos você acredita terem sido violados, URL específico de cada vídeo supostamente infrator, declaração de boa fé e de que as informações reputadas são verídicas, sob pena de responsabilização jurídica e informações de identificação (YOUTUBE, 2018a).

${ }^{12}$ Uma contranotificação é uma solicitação oficial para que o YouTube restabeleça um vídeo que foi removido por suposta violação de direitos autorais. Depois de avaliado o caso, o processo só será aplicado nos casos em que o envio tenha sido removido ou desativado como resultado de um erro, identificação incorreta do material a ser removido ou desativado, ou hipóteses de uso aceitável (YOUTUBE, 2018).

${ }^{13}$ A ferramenta de correspondência, por sua vez, funciona de forma semelhante ao Content ID: ela encontra envios idênticos aos vídeos originais em outros canais do YouTube. Quando uma correspondência é identificada, é possível analisá-la no YouTube Studio e o usuário pode decidir o que fazer. Entretanto, ele ainda é um "projeto piloto" da plataforma YouTube, e sua aplicação está sendo gradual aos canais que fazem parte do Programa de parcerias do YouTube e que têm mais de 100 mil inscritos (YOUYUBE, 2018).

${ }^{14}$ O Programa de Verificação de Conteúdo e a Ferramenta de Correspondência. O programa de verificação de conteúdo ajuda os proprietários de direitos autorais a pesquisar materiais que eles acreditam estar infringindo esses direitos e informações suficientes para que o YouTube possa localizar e remover esse material. Ele é destinado também, a empresas detentoras de direitos autorais, para que elas possam emitir várias solicitações de remoção de uma só vez (YOUTUBE, 2018).
} 
A FALIBILIDADE DO ALGORITMO CONTENT ID NA IDENTIFICAÇÃO DE VIOLAÇÕES DE DIREITO AUTORAL NOS VLOGS DO YOUTUBE: EMBATES SOBRE LIBERDADE DE EXPRESSÃO NA CULTURA PARTICIPATIVA

de dados do site. A partir disso, os proprietários podem tomar diferentes atitudes em relação a um material que corresponda ao conteúdo deles: bloquear a visualização de um vídeo inteiro; gerar renda com o vídeo ao veicular anúncios e, em alguns casos, compartilhar a receita com o usuário que fez o envio; ou rastrear as estatísticas de visualização do vídeo. Todas essas ações podem ser específicas para cada país (YOUTUBE, 2018a).

Mas ao contrário das reivindicações o YouTube só concede acesso ao Content ID a proprietários de direitos autorais que atendem a critérios específicos para serem aprovados, eles precisam deter direitos exclusivos sobre uma parcela considerável do material original enviado com frequência pela comunidade de usuários do YouTube (YOUTUBE, 2018a).

No caso do Contend ID, essas reivindicações são feitas por empresas proprietárias de músicas, filmes, programas de TV, videogames ou outros materiais protegidos por direitos autorais. Os proprietários do conteúdo podem configurar o Content ID para bloquear materiais do YouTube quando uma reivindicação é feita. Eles também podem permitir que o vídeo continue ativo no YouTube com anúncios. Nesses casos, a receita de publicidade é destinada aos proprietários dos direitos autorais do conteúdo reivindicado (YOUTUBE, 2018a).

O Content ID é ativado por parcerias, logo, as reivindicações não são acompanhadas por avisos de direitos autorais e não podem resultar na suspensão ou no encerramento do canal. No entanto, se o usuário receber uma reivindicação de Content ID e julgar que ela seja indevida ou incorreta, é possível disputá-la. Quando ocorre uma disputa de uma reivindicação como o proprietário dos direitos autorais é notificado e tem 30 dias para responder (YOUTUBE, 2018a).

A disputa pela reivindicação de Content ID deve levar em consideração os critérios de uso aceitável e de domínio público antes mesmo de ser iniciada. As disputas se aplicam apenas a casos em que o usuário que sofreu reivindicação tem todos os direitos necessários sobre o conteúdo do seu vídeo. O uso mal-intencionado ou abusivo do processo de disputa pode resultar em penalizações contra o vídeo ou o canal (YOUTUBE, 2018a).

Se a política estiver configurada para bloquear (não permitir que os usuários vejam o vídeo no YouTube) ou rastrear (permitir que os usuários vejam o vídeo sem anúncios), ela será temporariamente suspensa até sua disputa ser resolvida. Durante esse período, não é possível gerar receita com o vídeo (YOUTUBE, 2018a).

Como já mencionado, o Content ID não se destina para todo e qualquer usuário. É preciso que ele se qualifique e preencha certos requisitos. A aceitação de Content ID leva em 
consideração a necessidade real de cada candidato, que precisa provar que detêm direitos exclusivos ${ }^{15}$ sobre o conteúdo protegido por direitos autorais (YOUTUBE, 2018a).

Alguns itens não podem ser exclusivos a indivíduos, tais como: mashups, coletâneas, compilações e remixagens de outros trabalhos; gameplay em vídeo, recursos visuais de softwares e trailers; músicas e vídeos sem licença; músicas ou vídeos para os quais havia licença, mas sem exclusividade; gravações de apresentações (incluindo concertos, eventos, palestras e shows) (YOUTUBE, 2018a).

Caso aceitos para usar as ferramentas de Content ID, os candidatos precisam firmar um contrato declarando de forma expressa que somente conteúdos com direitos exclusivos podem ser usados como referências. Além disso, os candidatos aceitos precisam fornecer as localizações geográficas referentes à propriedade exclusiva, se ela não for mundial (YOUTUBE, 2018a).

Caso o usuário receba uma notificação de direitos autorais em razão de alguma referência, é possível que o usuário remova o conteúdo do vídeo que está sendo reivindicado, que pode ser, por exemplo, uma música ou trilha sonora. Agora, se o vídeo contém um áudio protegido por direitos autorais que foi reivindicado por Content $I D$, a ferramenta de troca de áudio silencia todo o áudio original do seu vídeo e o substitui pela faixa selecionada. (YOUTUBE, 2018)

O site também busca esclarecer para o usuário, que uma reivindicação não vai, obrigatoriamente, resultar na remoção do vídeo do bloqueio do canal, Reiteradamente, o YouTube faz as ressalvas de que o conteúdo reportado pode ser um caso de uso aceitável. O conceito de uso aceitável disponibilizado pelo YouTube é o que segue abaixo:

Uso aceitável é uma doutrina jurídica que autoriza a reutilização de materiais protegidos por direitos autorais sob determinadas circunstâncias, sem a necessidade da permissão do proprietário dos direitos autorais. Neste remix, pequenos excertos de materiais de diferentes origens são combinados para criar uma nova mensagem sobre o efeito da retórica provocativa em tempos de crise econômica. Obras que dão um novo significado ao material de origem podem ser consideradas de uso aceitável (YOUYUBE, 2018).

\footnotetext{
${ }^{15}$ A ideia de exclusividade do direito de autor se relaciona possibilidade de exploração econômica da obra, partindo do pressuposto de que a obra possui um valor econômico. Logo, há o direito reconhecido que possui o autor, de forma exclusiva de utilizar essa obra para fins econômicos (WACHOWICZ; SILVA, 2017). Estão elencados na LDA do art. 28 ao 38. Referem-se aos direitos de fruição e disponibilização do autor ou titular da obra. São direitos exclusivos porque dependem da prévia e expressa aprovação da autor, ou de quem o represente para serem reproduzidos, exibidos, expostos e/ou comunicados ao público, transmitidos ou baixados e etc. Se houverem rendimentos da exploração, deverão ser pagos royalties (ABRÃO, 2017, p.120).
} 
A FALIBILIDADE DO ALGORITMO CONTENT ID NA IDENTIFICAÇÃO DE VIOLAÇÕES DE DIREITO AUTORAL NOS VLOGS DO YOUTUBE: EMBATES SOBRE LIBERDADE DE EXPRESSÃO NA CULTURA PARTICIPATIVA

É importante mencionar, que o "uso aceitável" é uma tradução do termo "fair use que designa uma doutrina adotada pelos sistemas de direito autoral copyright, tais como o americano. Na Inglaterra e Canadá, (também sistemas copyright) existe o fair dealing, que possui algumas diferenças entre o fair use. Entretanto, seus objetivos são semelhantes, isto é, disciplinar casos em que os direitos autorais precisam ceder em face do interesse público, da liberdade de expressão e ao acesso à informação (D’AGOSTINO, 2008, p. 344).

O sistema pátrio de direito autoral, por outro lado, adotou a matriz continental, filiandose ao sistema francês Droit d'auteur. Nesses sistemas, não há previsões de fair use ou fair dealing. Entretanto, existem as limitações e exceções de direito de autor que cumprem função semelhante.

Na Lei de Direitos Autorais (Lei 9.610/98) as limitações de direito de autor encontramse entre os artigos 46 e 48. De acordo com Abrão (2017, p.169), todas as legislações de países signatários da Convenção de Berna, como é o caso do Brasil, essas limitações existem para assegurar o acesso ao conhecimento, a cultura e ao lazer. Elas constituem os "usos justos" das legislações baseadas no modelo francês. Eles se mostram justos porque entende-se que toda a sociedade colaborou com o autor na criação da obra, resultado de tudo que o autor viu, leu, ouviu e participou dentro de um contexto histórico.

Esta previsão foi ratificada na revisão da Convenção em 1971, no seu artigo 9², item 2:

Fica reservado às legislações dos países da União a faculdade de permitir a reprodução de tais obras (obras literárias e artísticas protegidas pela Convenção de Berna) em determinados casos especiais, de tal modo que a reprodução não cause prejuízo injustificado aos interesses legítimos do autor.

Esta regra também é conhecida como "Regra dos Três Passos", prevista na Convenção de Berna e suas revisões, bem como no Acordo TRIPS. Ela traz diretrizes para os países signatários adotarem em suas legislações pátrias, bem como serve também para analisar se um

\footnotetext{
${ }^{16}$ A doutrina do "fair use", que pode ser traduzida como "uso justo" ou "uso aceitável" existe na lei de copyright americana que prevê algumas exceções para a exclusividade da utilização pelo detentor dos direitos autorias de um material protegido pela lei. Ou seja, se houverem objetivos "limitados" e "transformadores", tais como paródias, críticas e comentários, estes podem ser realizados sem a anuência do detentor dos direitos, não configurando violação. O fair use americano também alcança as situaçãoes de divulgação de conteúdos na imprensa, de cunho jornalistico e informativo, e também a realização de cópias de obras para serem usadas em sala de aula, com fins educacionais. Há uma lista de requistos que precisam ser cumpridos para que a ação possa ser enquadrada como uso justo. Estas exceções devem atender quatro requisitos para se encaixarem no uso aceitável: 1) propósito e o caráter do uso; 2) A natureza do trabalho protegido por direitos autorais; 3) O montante do trabalho que será usado em relação a todo o trabalho protegido por direitos autorais; e 4) O efeito que o uso teria no mercado ou o valor do trabalho protegido por direitos autorais. (D'AGOSTINO, 2008, p. 344)
} 
determinado uso infringiu leis de direito de autor. Alguns autores do direito autoral, como Maristela Basso (2007) entendem que embora não tenha sido adotada de forma expressa, ela foi incorporada pela LDA de forma implícita, no artigo 46, VIII.

No site do YouTube, a descrição do uso justo é baseada no modelo americano de fair use, onde um dos critérios mais importantes na análise é o aspecto "transformativo" da obra, isto é, se está sendo acrescentada uma contribuição, significado ou forma de expressão. Algo que é meramente uma cópia do original não se enquadra no uso justo.

\section{LIBERDADE DE EXPRESSÃO E O ALGORITMO CONTEND ID}

Nos termos de serviço do YouTube é permitido o uso de conteúdo de terceiros, desde que não esteja protegido por direitos autorais: "Você afirma que não enviará material protegido por direitos autorais, por segredo de negócio ou de qualquer outra forma protegido por direitos de terceiros, a menos que Você tenha permissão do legítimo proprietário do material ou caso. [...]" YOUTUBE, 2018c).

Logo, o problema não é colocar conteúdo de terceiros em seus vídeos, mas desrespeitar direitos autorais colocando materiais que estejam protegidos. Ocorre que, via de regra, esses materiais de terceiros estão protegidos pelo direito de autor.

Entretanto, existem exceções, que são situações em que os direitos autorais precisam ceder em favor de outros interesses e direitos, como a liberdade de expressão, por exemplo. São as limitações do direito de autor, contidas no artigo 46 e seguintes da LDA, em que estão contidas as hipóteses em que o uso de material de terceiros não constitui ofensa ao direito autoral (SILVA, 2016).

Estes artigos elencam uma série de situações em que não se configura uma violação de direito autoral. São os casos, por exemplo, das paródias, paráfrases e reprodução na imprensa diária. É perfeitamente possível e legal a utilização de trechos de obras com a finalidade de realizar uma análise, crítica ou polêmica, caso em que se está diante de uma citação, amparada pelo art. 46, III da $\mathrm{LDA}^{17}$ :

\footnotetext{
${ }^{17}$ Art. 46. Não constitui ofensa aos direitos autorais:

III - a citação em livros, jornais, revistas ou qualquer outro meio de comunicação, de passagens de qualquer obra, para fins de estudo, crítica ou polêmica, na medida justificada para o fim a atingir, indicando-se o nome do autor e a origem da obra (BRASIL, 1998);
}

Rev. de Direito, Inovação, Propriedade Intelectual e Concorrência | e-ISSN: 2526-0014 | Porto Alegre | v. 4 | n. 2 | p. $43-62$ | Jul/Dez. 2018 
A FALIBILIDADE DO ALGORITMO CONTENT ID NA IDENTIFICAÇÃO DE VIOLAÇÕES DE DIREITO AUTORAL NOS VLOGS DO YOUTUBE: EMBATES SOBRE LIBERDADE DE EXPRESSÃO NA CULTURA PARTICIPATIVA

É claro que essas exceções são permitidas desde que ocorra referência do autor da obra e informações que a identifiquem. A citação, por exemplo, é recurso amplamente utilizado nos trabalhos acadêmicos e científicos.

Um exemplo é o caso do professor de Direito Cláudio Henrique da Silva (2016) que possui um canal no YouTube onde posta vídeos sobre assuntos que possam complementar suas aulas. Em um de seus vídeos, seu objetivo era comentar alguns trechos de uma entrevista transmitida pelo programa "Roda Viva", cujos direitos são detidos pela Fundação Padre Anchieta. Ao upar o vídeo para o site, no qual reproduzia um pequeno trecho do vídeo afim de comentá-lo, Silva recebeu uma reivindicação do Content ID, pois o algoritmo verificou uma correspondência. Silva (2016) entende que estaria amparado pelo art. 46, III da LDA, uma vez que trata-se de uma citação para efeitos de polêmica e de discussão do tema. O autor do vídeo fez uma contranotificação, justificando seu uso. A fundação detentora dos direitos teve um entendimento diverso, de maneira que o vídeo, upado em 7 de julho de 2016, continua bloqueado com base nos direitos autorais ${ }^{18}$.

A citação independe de autorização prévia, sendo necessária a transmissão do conhecimento e do ensino. De acordo com Abrão (2017, p.173) pode-se falar inclusive em um “direito de citação". Este direito está condicionado a alguns requisitos: a obra citada deve ser anterior a que está sendo elaborada; a obra tenha sido acessada por meios lícitos; finalidade de crítica, polêmica ou estudo; citação tenha finalidade para "usos honrados", de acordo com a Convenção de Berna (itens 10,1).

Silva (2016) explica que reproduziu uma parte muito pequena da obra, cerca de $2 \%$ de uma entrevista que tinha cerca de uma hora e vinte dois minutos, totalizando 00:01:49. Muitas vezes, com $2 \%$ de reprodução do material não é nem mesmo possível identificar a obra. Logo, isto não descaracteriza a obra, não a substituiu nem tira sua atratividade.

A falibilidade do algoritmo Content ID também já foi levantada em outras oportunidades, tanto pela academia por meio de artigos, como também fora dela, em palestras, reportagens na mídia e relatos de youtubers. De acordo com Silveira $(2015$, p.5) concluiu que existem pontos que tornam o Content ID um algoritmo frágil e extremamente rígido: as indefinições das leis e termos de uso; inflexibilidade das empresas de mídia ao protegerem o seu conteúdo; erros e abusos que o Content ID está sujeito; a importância das Networks para a legitimação do trabalho dos YouTubers.

${ }^{18}$ Disponível em: <https://www.youtube.com/watch?v=r6BjOh78wDw> Acesso em: 18 de julho de 2018. 
No final de 2013, as políticas de direito autoral do site de streaming YouTube mudaram. Alterações para termos mais rigorosos estavam sendo feitas e testadas pela Google, com a implantação do sistema Contend ID, que permite uma análise mais precisa e rigorosa no exame de vídeos na busca por violações de direito autoral. Nesse tempo, o que se sucedeu foi que não apenas canais que reproduziam na íntegra os conteúdos de terceiros, como os que veiculam filmes, capítulos de novelas e seriados, (onde efetivamente ocorrem violações) foram notificados ou até suspensos do ar, mas também canais que integravam Networks e se utilizavam de trechos destes produtos midiáticos em outras apropriações para comentários críticos, análises e paródias (SILVEIRA, 2015, p.2).

Há casos como relata Silveira $(2015$, p.8) em que os canais de cinco youtubers foram bloqueados e os conteúdos removidos em decorrência de supostas violações de direitos autorais. As notificações partiam de empresas de mídia grandes, tanto nacionais como a Rede Globo, como internacionais como Nintendo, Sony, Fox e Warner. Muitas vezes, as notificações vieram por causa de trailers que tiveram segundos exibidos com a intenção de comentá-los. Para a autora, isso expõe uma relação conflituosa com as apropriações criativas dos usuários de redes sociais na internet.

O Content ID apresenta também, algumas falhas técnicas pois youtubers e alguns jornalistas relataram alguns erros de identificação nesse período. E quanto aos abusos, pode-se questionar a abertura que algumas empresas de mídia encontraram para se "aproveitarem do algoritmo", para retirada de material e monetizar sobre os vídeos que não lhes pertenciam (SILVEIRA, 2015, p.10).

Um caso emblemático foi o do Canal Nostalgia ${ }^{19}$, que em 2014 quase foi fechado porque atingiu o número máximo de notificações por direitos autorais. O canal apresenta vídeos relacionados à cultura popular e ao entretenimento, fazendo apanhados de objetos, jogos, programas de televisão lembrados pelo público (SILVEIRA, 2015, p.10).

Para tanto, o canal utilizava inúmeras imagens e sons de terceiros, remixados ou usados como ilustração para os comentários do YouTuber. As notificações partiram de grandes empresas internacionais (Warner Bros. Entertainment e Fox Broadcasting Company), mostrando-se importante para a resolução do problema as negociações estabelecidas pela Network do canal, a Amazing Pixel (SILVEIRA, 2015, p.10). Além disso, o vlogger recebeu apoio de muitos fãs e de outros youtubers, como o canal Coisa de Nerd.

19 O vlogger esclarece o ocorrido em um vídeo, de janeiro de 2014: https://www.youtube.com/watch?v=xONWXUDZWrY Acesso em 29 de julho de 2018. 
Em 2017, por exemplo, o canal Marcio Guerra Canto sofreu um "strike" do site Youtube. Ele teve seu canal e conta bloqueados e um vídeo, que supostamente estaria infringindo leis de direito autoral, retirados do site. Márcio Guerra é professor de canto, e possui dois canais no YouTube, sendo que em um deles, (o canal que foi bloqueado) ele faz análises e comentários técnicos sobre as performances de cantores famosos. Para tanto, ele reproduz trechos de vídeos destes cantores, em um monitor ou televisão no local onde está gravando o vídeo. No caso em comento, tratava-se de uma exibição de trechos do programa The Voice Brasil, cujos direitos pertencem à Rede Globo. ${ }^{20}$

As Networks ${ }^{21}$ estabelecidas pelos youtubers são uma parte importante na relação de atores, empresas e direitos autorais. Elas consistem em empresas terceirizadas que possuem uma concessão do site para administrar a monetização ${ }^{22}$ de um conjunto de canais de um mesmo segmento. Elas são importantes para os youtubers porque geram credibilidade e legitimidade aos canais parceiros em relação ao uso justo de materiais de terceiros (SILVEIRA, 2015, p.10).

No que se refere as empresas de mídia, Silveira $(2015$, p.7) explica que as mesmas agem buscando estabilizar a questão, pressionando o YouTube para tomar medidas na defesa dos usos de seus produtos. Para a autora, tomando estas empresas como atores importantes desta relação, a rigidez do Content ID está relacionada com as pressões por elas exercidas.

Há uma relação conflituosa estabelecida com as apropriações criativas dos usuários de redes sociais na internet. Em sua maioria, essas empresas não permitem qualquer uso criativo de suas obras, mesmo que seja feito sem fins lucrativos. Essa inflexibilidade é evidente quando, pois, até mesmo quando os YouTubers utilizam materiais feitos para divulgação, como por exemplo, trailers de filmes e recebem reivindicações, mesmo que tenham sido feitos com intenção apenas de comentá-los (SILVEIRA, 2015, p.7).

\footnotetext{
${ }^{20}$ A controvérsia pode ser compreendida assistindo ao vídeo que o próprio youtuber postou. Disponível em: < https://www.youtube.com/watch?v=PACwUzeyaj0> Acesso em 12 de fevereiro de 2018.

${ }^{21}$ As Networks constituem-se de empresas terceirizadas que possuem uma concessão do site para administrar a monetização de um conjunto de canais de um mesmo segmento. Também se tornaram importantes para credibilidade e legitimidade que essas empresas conferiam aos canais parceiros em relação ao uso justo de materiais de terceiros (SILVEIRA, 2015).

${ }^{22}$ Até janeiro de 2018 vários produtores de conteúdo poderiam conseguir remuneração com base nos anúncios que eram veiculados no início de seus vídeos, desde que fizessem parte do Programa de Parcerias do site, cujos requisitos eram: produzir conteúdo original e com regularidade; o conteúdo deve obedecer às regras da Comunidade do YouTube e estar localizado em um pais que fizesse parte do Programa de Parcerias. Mas em 16 de janeiro de 2018 as regras mudaram. Os requisitos incluíram ter mais de mil inscritos no canal e atingir quatro mil horas de exibição nos últimos 12 meses, para que ele possa então, ser analisado para participar do programa (YOUTUBE, 2018d). Um dos motivos que impulsionaram essa mudança foi que anúncios publicitários estavam sendo veiculados em vídeos com conteúdo duvidoso, e muitas empresas anunciantes não queriam ver sua marca associadas a certos tipos de conteúdo. Um caso que ganhou notoriedade foi o escândalo envolvendo o vlogger americano Logan Paul.
}

Rev. de Direito, Inovação, Propriedade Intelectual e Concorrência | e-ISSN: 2526-0014 | Porto Alegre | v. 4 | n. 2 | p. $43-62$ | Jul/Dez. 2018 
Também, existem relatos de usos abusivos de usuários por parte de usuários do Content $I D$, principalmente empresas de mídia que reivindicavam materiais que não tinham os direitos, de forma proposital, para monetizar os vídeos no lugar dos vloggers. De outro lado, alguns vloggers fizeram vídeos demonstrando como poderiam burlar o algoritmo, que ensinam formas de editar os vídeos e inserir elementos nas imagens para confundir o Content ID (SILVEIRA, 2015).

Outro aspecto que vale salientar, é que o Content ID foi criado em 2007 em um contexto em que ainda havia pouco conteúdo no site, uma vez que o próprio YouTube foi criado em 2005. Na época, muitos usuários começaram a disponibilizar conteúdo pirata no site, como cópias integrais de filmes e programas de TV e músicas. Mas o foco de identificação do algoritmo nem mesmo é este tipo de material, pois como visto até agora, ele também considera violação as apropriações criativas que utilizam materiais de terceiros.

Outro caso recente que aponta a falibilidade do algoritmo é do músico e professor de música australiano Sebastian Tomczak. Ele publicou, em 2015, um vídeo de mais de dez horas de duração sem imagem, apenas sonorizado com ruído branco, uma junção de acordes que resulta num som similar ao de um antigo canal de televisão fora do ar. Ele recebeu cinco queixas de violação de direitos autorais, todas através do Content ID do YouTube. O objetivo do experimento seria verificar a capacidade da ferramenta do YouTube de determinar, com precisão, quando há um caso efetivo de uso de acordes e trechos de músicas alheios (UBC, 2018).

\section{CONCLUSÃO}

Observou-se que os algoritmos são operações lógico-finitas, um conjunto de procedimentos que procuram solucionar problemas e funcionam estabelecendo um padrão que deve ser seguido. A política de direitos autorais adotada pelo site YouTube e quais ferramentas ele oferece ao usuário para coibir violações de Direito Autoral. Também neste item, viu-se que os vlogs podem ser considerados um produto da cultura participativa e um desdobramento dos antigos blogs pessoais.

Neste contexto, observa-se uma classe que está se "profissionalizando" no streaming de vídeos, na produção de informação e conteúdo que precisam de legitimidade, segurança e formalização. De outro ponto, existem os sujeitos que não visam diretamente o lucro, mas utilizam as redes e o Youtube como ferramenta para se expressarem, fazerem contribuições e 
A FALIBILIDADE DO ALGORITMO CONTENT ID NA IDENTIFICAÇÃO DE VIOLAÇÕES DE DIREITO AUTORAL NOS VLOGS DO YOUTUBE: EMBATES SOBRE LIBERDADE DE EXPRESSÃO NA CULTURA PARTICIPATIVA

participarem da construção de cultura nas redes sociais. Surgem então, novas demandas a serem discutidas no âmbito jurídico, e neste caso, no âmbito do Direito Autoral.

A análise centrou-se na ferramenta que é objeto principal desta pesquisa, o Content ID. O algoritmo busca por correspondências nos vídeos enviados ao site YouTube, tendo como base para análise, um banco de referências que é fornecido pelos usuários que estão qualificados para utiliza-lo. Normalmente, gravadoras, empresas de mídia e entretenimento. Quando uma correspondência for encontrada, o usuário recebe uma notificação e pode ser o vídeo ou apenas o áudio bloqueado, monetizado pelo usuário detentor dos Direitos Autorais, ou até mesmo ter o canal bloqueado.

Destacou-se a problemática que envolve a aplicação do Content ID. O YouTube, permite o uso de materiais de terceiros, salvo se protegidos pelo Direito de Autor. Ainda assim, é preciso considerar as hipóteses de limitações ao Direito de Autor, uma vez que em nosso sistema de proteção não há a previsão de "uso justo" tal como nos sistemas de copyright.

Também foi possível observar que a falibilidade pode ser encontrada não só no algoritmo, mas também nas outras ferramentas de reivindicação de direitos autorais. Muitos vloggers tiveram suas contas bloqueadas por notificações de Direito Autoral.

A hipótese corroborada foi a de que o uso do Content ID do YouTube, pode gerar conflito entre liberdade de expressão e de direitos autorais, em razão de sua falibilidade na aplicação prática. O Content ID não analisa a possibilidade de uso aceitável, ou limitações de direito autoral, apesar de isto estar descrito nas diretrizes de direitos autorais do site, uma vez que os algoritmos trabalham com soluções lógicas para problemas idênticos, o que se tem é a aplicação de uma solução única para todos os casos, isto é, o bloqueio do vídeo (ou até mesmo, a conta do usuário caso reivindicações de direitos autorais ocorram repetidamente) ou do áudio. Casos como citações, paráfrases e reproduções que não prejudiquem a obra ou o autor não podem ser objeto de veto, sob pena de obstar a liberdade de expressão. A própria LDA fez estas ressalvas criando institutos como as limitações ao direito de autor.

É preciso aperfeiçoar estas ferramentas visando a segurança de que a não haverá abusos cometidos (por parte de grandes empresas de entretenimento, bem como de outros produtores de conteúdo) sob respaldos de proteção ao Direito Autoral, visando impedir um movimento de crítica ou análise por parte de outros sujeitos. Casos como estes poderiam abrir margem para a limitação da liberdade de expressão dos sujeitos, criando uma espécie de censura.

Rev. de Direito, Inovação, Propriedade Intelectual e Concorrência | e-ISSN: 2526-0014 | Porto Alegre | v. 4 | n. 2 | p. 43-62 | Jul/Dez. 2018 


\section{REFERÊNCIAS}

ABRÃO, Eliane Y. Comentários à lei de direitos autorais e conexos: Lei 9610/98 com as alterações da lei 12.853/2013 e jurisprudência dos Tribunais Superiores. Rio de Janeiro: Lumen Juris, 2017.

BASSO, Maristela. As exceções e limitações aos direitos do autor e a observância da regra do teste dos três passos (three-step-test). Revista da Faculdade de Direito da Universidade de São Paulo v. 102 p. $493 \quad$ - $503 \quad$ jan./dez. 2007. Disponível em:<http://www.egov.ufsc.br/portal/sites/default/files/67766-89196-1-pb.pdf> Acesso em 01 de agosto de 2018.

BRASIL. Lei de Direitos Autorais (Lei no 9.610, de 19 de fevereiro de 1998) Disponível em: < http://www.planalto.gov.br/ccivil_03/leis/L9610.htm> Acesso em 26 janeiro de 2018.

CONVENÇÃO DE BERNA para a proteção das obras literárias e artísticas. Disponível em:< http://www.unesco.org/culture/natlaws/media/pdf/bresil/brazil_conv_berna_09_09_1886_por _orof.pdf> Acesso em 01 de agosto de 2018.

CECILIO, Leandro Rezende. Programando multidões: algoritmos, revoluções e democracia. In: BELLO, Enzo; RIBEIRO, Samantha S. Moura, (orgs.). Democracia nos meios de comunicação: pluralismo, liberdade de expressão e informação. Rio de Janeiro: Lumen Juris, 2016.

COMBE, C., \& CODREANU, T.. Vlogging: a new channel for language learning and intercultural exchanges. In S. Papadima-Sophocleous, L. Bradley \& S. Thouësny (Eds), CALL communities and culture - short papers from EUROCALL 2016 (pp. 119-124), 2016. Researchpublishing.net. Disponível em: <https://doi.org/10.14705/rpnet.2016.eurocall2016.548> Acesso em 01 de agosto de 2018.

CORUJA, Paula. Vlog como gênero no youtube: a profissionalização do conteúdo gerado por usuário. Comunicologia (Revista de Comunicação da Universidade Católica de Brasília) Brasília, UCB, v. 10, n. 1, p. 46 - 66, jan./jun. 2017. Disponível em:

$<$ https://portalrevistas.ucb.br/index.php/RCEUCB/article/viewFile/8128/5125> Acesso em 01 de agosto de 2018.

D'AGOSTINO, Giuseppina. Healing Fair Dealing? A Comparative Copyright Analysis of Canada's Fair Dealing to U.K. Fair Dealing and U.S. Fair Use. 2008. Disponível em:< http://lawjournal.mcgill.ca/userfiles/other/7046615-dAgostino.pdf > Acesso em 14 de junho de 2018.

DORNELLES, Juliano Paz. O fenômeno Vlog no Youtube: análise de conteúdo de Vloggers brasileiros de sucesso / Juliano Paz Dornelles. Dissertação de Mestrado - Faculdade de Comunicação Social, Pós-Graduação em Comunicação Social. Porto Alegre, PUCRS, 2015.

FERRARI, Fabricio; CECHINEL, Cristian. Introdução a programação e algoritmos. 2018. Disponível em:<https://lief.if.ufrgs.br/pub/linguagens/FFerrari-CCechinel-Introducao-aalgoritmos.pdf $\geq$ 


\section{A FALIBILIDADE DO ALGORITMO CONTENT ID NA IDENTIFICAÇÃO DE VIOLAÇÕES DE DIREITO AUTORAL NOS VLOGS DO YOUTUBE: EMBATES SOBRE LIBERDADE DE \\ EXPRESSÃO NA CULTURA PARTICIPATIVA}

JENKINS, Henry. Cultura da Convergência. 2. ed. São Paulo: Aleph, 2009

MICHAELIS, Dicionário on-line da língua portuguesa. Algoritmo. Disponível em:< https://michaelis.uol.com.br/moderno-portugues/busca/portugues-brasileiro/algoritmo/\%3E $>$ Acesso em 23 de julho de 2018

PARISIER, Eli. O Filtro invisivel que a internet esconde de você. Jorge Zahar, Rio de Janeiro, 2011.

SILVA, Cláudio Henrique Ribeiro da., Limitações aos direitos autorais no Youtube e o Content ID: Reflexões Extraclasse. Postado em 30 de Novembro de 2016. Vídeo aula disponível em: < https://www.youtube.com/watch?v=8_-uvBYbY0I> Acesso em 04 de julho de 2018.

SILVEIRA, Letícia Lopes da. Uso justo ou violação? Controvérsias sobre direitos autorais no YouTube. Anais do XXXVIII Congresso Brasileiro de Ciências da Comunicação: Rio de Janeiro, RJ, 2015. Disponível em:

< http://portalintercom.org.br/anais/nacional2015/resumos/R10-0707-1.pdf> Acesso em 16 de fevereiro de 2018.

UBC. União Brasileira de Compositores. Facebook anuncia ferramenta para coibir vídeos que violem direitos autorais musicais. São Paulo, 2017. Disponível em:

< http://www.ubc.org.br/publicacoes/noticias/6540>. Acesso em 29 de julho de 2018.

UBC. União Brasileira de Compositores. Ferramenta que combate violações de direitos autorais é posta em xeque. São Paulo, 2018 Disponível em: <http://www.ubc.org.br/publicacoes/noticias/9022> Acesso em 29 de julho de 2018.

WACHOWICZ, Marcos; SILVA, Rodrigo Otávio Cruz e. Os limites da publicação de conteúdo produzido em estabelecimento de ensino: Estudo de caso entre a Lei dos Direitos Autorais e o Marco Civil da Internet. In: Temas Contemporâneos de Propriedade Intelectual. BACELAR, Ricardo (org.), 2017. Disponível em: <http://www.gedai.com.br/?q=ptbr/content/os-limites-da-publica\%C3\%A7\%C3\%A3o-na-internet-do-conte\%C3\%BAdoproduzido-pelo-professor-em-sala-de-aula > Acesso em 26 de janeiro de 2018.

YOUTUBE, (2018). O que é uso aceitável? Disponível em:

$<$ https://www.youtube.com/yt/about/copyright/fair-use/\#yt-copyright-four-factors > Acesso em 29 de julho de 2018

YOUTUBE, (2018a). Enviar uma notificação de remoção por direitos autorais. Disponível em: https://support.google.com/youtube/answer/2807622?hl=pt-BR. Acesso em 29 de julho de 2018.

YOUTUBE, (2018b) O que é uma reivindicação do Content ID?.Disponível em: <https://support.google.com/youtube/answer/6013276?hl=pt-BR\&ref_topic=2778545> Acesso em 29 de julho de 2018. 
YOUTUBE, (2018c). Termos de Serviço. Disponível em: < https://www.youtube.com/static?gl=BR\&template=terms\&hl=pt $>$ Acesso em 29 de julho de 2018

YOUTUBE, (2018d). Como gerar receitas com seus vídeos. Disponível em:

<https://support.google.com/youtube/answer/72857?hl=pt-BR > Acesso em 29 de julho de 2018. 